\title{
Electric vehicle drivers use better strategies to counter stereotype threat linked to pro-technology than to pro-environmental identities
}

Authors: Naomi King ${ }^{a}$, Mark Burgess ${ }^{a}$, and Margaret Harris ${ }^{a}$

a Psychology, Oxford Brookes University, Headington Campus, Oxford, OX3 OBP, United Kingdom

Correspondence should be addressed to: Naomi King, Psychology, Faculty of Health and Life Sciences, Oxford Brookes University, Headington Campus, Oxford, OX3 0BP, United Kingdom.

Email: nking@brookes.ac.uk 


\begin{abstract}
Battery electric vehicles (BEVs) could play a crucial role in reducing greenhouse gas emissions around the world. Much research has examined the practical barriers to large-scale BEV uptake, but very little has examined the psychological barriers. The current study addresses this gap in the literature by investigating the effects of stereotype threat on BEV drivers. This psychological predicament occurs when an individual imagines or experiences being judged in terms of negative stereotypes about their social group. Qualitative thematic analysis of interview data revealed three distinct stereotypes that the BEV drivers imagined or reported other people to hold: eccentric, low-status environmentalists; hypocritical, highstatus environmentalists; and geeky technophiles. With regard to the first and second stereotypes, drivers tended to use individualist defence strategies by downplaying their proenvironmental attitudes and dissociating themselves from the undesirable environmentalist groups. With regard to the third stereotype, they tended to use more constructive, group-level defence strategies by perceiving their BEV driver ingroup as superior on the innovative technology adopter dimension compared to their non-BEV driver outgroup. Suggestions are made for countering the psychological barrier of stereotype threat, such as promoting images of BEV drivers as future-shaping market leaders and treating them as members of an influential and desirable consumer group.
\end{abstract}

Keywords: electric vehicles; stereotype threat; consumer identity; environmentalists; technophiles; innovative technology adoption

Declarations of interest: none. 
1

2

3

4

5

6

7

8

9

\section{Introduction}

The need to increase mainstream market uptake of electric vehicles (EVs) is becoming a major concern for governments around the world. New regulations to reduce greenhouse gas emissions that contribute to global warming require alternatives to vehicles powered by the traditional internal combustion engine (ICE). Pure battery EVs (BEVs) present a key solution for decarbonising the transportation sector. Widespread adoption would also improve local air quality by removing other harmful ICE tailpipe emissions (Department for Environment, Food and Rural Affairs [Defra] \& Department for Transport [DfT], 2017). The UK government plans to end the sale of all new ICE cars and vans by 2040, and for almost every car and van to be a zero emission vehicle by 2050 (Defra \& DfT, 2017). However, the number of non-commercial BEV cars $(13,597)$ registered in the UK in 2017 formed only $0.54 \%$ of the total number of non-commercial cars (Society of Motor Manufacturers and Traders [SMMT], 2018a). This rose by just $0.03 \%$ in the first 6 months of 2018 (SMMT, 2018b).

An extensive body of research has analysed the practical barriers to BEV uptake, including high upfront purchase costs, limited driving range, and insufficient public charging infrastructure (DfT, 2016). The problem with these barriers is that they are easy to identify, but difficult to remove. This is partly due to a 'chicken and egg' situation (Office for Low Emission Vehicles, 2013, pp. 11, 31), whereby stakeholders are unwilling to make significant financial investments until a sufficient number of BEVs have been purchased, but the majority of mainstream consumers want to see these hurdles removed before considering a switchover to the unfamiliar technology. In comparison, psychological barriers to BEV uptake have received little attention. This is surprising, given that car choice is closely tied to issues of image and identity (Grubb \& Hupp, 1968; Heffner, 2007; Sowden \& Grimmer, 2009; Steg, 2005; Steg, Vlek, \& Slotegraaf, 2001). People often make judgments about others 
based on their choice of car, inferring their personality traits and social positions by drawing on car owner stereotypes linked to certain types or brands (Belk, 2004; Grubb \& Hupp, 1968; Sowden \& Grimmer, 2009). The current study addresses this important gap in the EV literature. Specifically, it examines the perspectives of BEV drivers in a large-scale UK BEV trial, who regarded BEVs as desirable on a personal level but often believed other people to see BEV drivers in a negative light.

A very small body of research has touched on the topic of undesirable identities linked to EVs (for overviews, see Burgess, King, Harris, \& Lewis, 2013; Bennett \& Vijaygopal, 2018). EV drivers' own perceptions of undesirable identities emerged from interview data in the UK (Burgess et al., 2013; Graham-Rowe, Gardner, Abraham, Skippon, Dittmar, Hutchins, et al., 2012) and the US (Heffner, 2007). Although not the main focus of these studies, some BEV or hybrid EV (HEV) drivers expressed concern that other people might see them as an 'eco warrior' (Burgess et al., 2013, p. 39), a 'tree-hugger' (Heffner, 2007, p. 407), a 'spinster lady currently working in a library, hugging trees and going to public meetings about saving the planet' (Graham-Rowe et al., 2012, pp. 147-148), or a 'socially-challenged geek' (Heffner, 2007, p. 164). In most of these cases, the drivers did not appear to actually encounter such stereotypes, but simply assumed that members of the public might perceive them in this way.

Why would EV drivers make such assumptions? The above research did not answer this question directly, although a number of UK EV drivers reported real-world interactions with people who were sceptical about the cars, seeing them as strange, unviable, and inferior to their ICE counterparts (Burgess et al., 2013; Graham-Rowe et al., 2012). These images carried the implication that EV drivers were also regarded as strange and inferior. This view is sometimes expressed in the media and social media, where EVs have been described as 'tools for fools' and their owners as 'not very bright' (Clarkson, as cited by Sunday Times 
51 Driving, 2013, paras 9, 15). A survey of 445 residents of London found similar 'ingrained negative associations' of EVs, alongside a general perception that they were a 'niche idea that appeals to techy early adopters or the "super green" (Transport for London [TfL], 2016, pp. 23-24). These two distinct consumer categories are linked to multiple meanings, which may be very positive for those who identify with either group, but may be associated with negative stereotypes for those outside the groups.

To give an example of environmentalist stereotypes, one issue of The Sunday Times Magazine (a publication renowned for high-quality journalism) focused on the topic of global warming. Despite its strong emphasis on the need to address this problem, various articles made reference to 'tree-hugging, soft-headed warmists'; 'dinner-party eco-warriors' (Appleyard, 2009, pp. 12, 11); the 'eco-nutter'; the 'shouty mob of eco-protesters'; the 'green fringe' (Hattersley, 2009, pp. 29, 31); and the 'eco-hypocrites' who go around 'spouting green virtue but spewing out hundreds of tons of carbon from their private jets or multiple holiday homes around the globe' (Foreman, 2009, pp. 52, 54). Although the authors attempted to disprove these stereotypes, the use of such descriptions nevertheless functioned to invoke and reinforce the impression that people with pro-environmental attitudes occupy a unique social group that attracts and deserves a certain amount of ridicule. With regard to technophile stereotypes, these are often based on the image of the 'geek', which can be defined as 'a peculiar person ... unfashionable, or socially awkward' (Dictionary.com, n.d.). Rose (2003) described how a globally popular series of computer manuals continually belittled IT experts by joking derisively about 'nerd programmers', 'techogeeks', and 'computer dweebs' who differ substantially from 'normal people' (p. 123).

$$
\text { Together, this evidence suggests that EV drivers (and potential EV drivers) face a }
$$
considerable psychological dilemma. Several studies propose that EVs may appeal initially to people with strong pro-environmental or pro-technology attitudes (e.g., Axsen \& Kurani, 
2013; Egbue \& Long, 2012; Heffner, 2007; Schuitema, Anable, Skippon, \& Kinnear, 2013;

White \& Sintov, 2017). Such individuals might see the psychological benefits of driving an

EV (e.g., feeling good about protecting the environment or being an early adopter of innovative technology) to outweigh the practical barriers. However, this would be undermined if drivers are simultaneously confronted with a belief that other people might see them through the lens of a negative stereotype. The current study examines this dilemma by drawing on the well-established theory of 'stereotype threat'.

\subsection{Stereotype threat}

Stereotype threat occurs when an individual imagines or experiences being judged and potentially treated by others in terms of a negative stereotype about their social group, or fears that they are confirming this stereotype in their own eyes or in the eyes of others (Aronson, 2002; Steele, 1997; Steele, Spencer, \& Aronson, 2002; see also Shapiro \& Neuberg, 2007, for discussion of the definition of stereotype threat). It evolved as a microtheory of social identity theory, which examines intergroup relations and collective behaviour (Tajfel, 1978; Tajfel \& Turner, 1979). Stereotype threat can have a significant impact on people's attitudes and behaviours in stereotype-relevant domains. It is a predicament that affects a broad array of groups and domains of activity, and as everyone has some form of social identity for which a negative stereotype exists, virtually everyone will experience stereotype threat at some time (Aronson, 2002; Steele et al., 2002). It can be activated by various types of situational cues, ranging from explicit discriminatory behaviour to 'the mere threat of discrimination and devaluation implied by the perceived relevance of a negative group stereotype' (Steele et al., 2002, p. 389). Individuals may experience different kinds of stereotype threat, ranging from a brief sense of apprehension linked to a specific activity to a continuous 'engulfing predicament' over a long time period (Steele et al., 2002, p. 385). 
The large majority of studies applying this theoretical framework have assessed the effect of negative stereotypes on performance tasks (e.g., intellectual or athletic tasks), and found that experience of stereotype threat generally decreases performance (see Pennington, Heim, Levy, \& Larkin, 2016, for a review). Many studies have shown, for example, that female participants perform less well than males on mathematical tasks in contexts which trigger the stereotype of women having poorer mathematical ability than men (e.g., Lesko \& Corpus, 2006; Sekaquaptewa \& Thompson, 2003; Spencer, Steele, \& Quinn, 1999). A much smaller number of studies have found that stereotype threat has a negative impact in other domains, including healthcare decisions and outcomes (Abdou \& Fingerhut, 2014), leadership aspirations (Davies, Spencer, \& Steele, 2005), and financial decision-making (Carr \& Steele, 2010). Despite extensive research on the topic of stereotype threat, however, almost all studies have used experimental or questionnaire methods, and focused on stereotypes linked to stable and pre-determined identities such as gender and ethnicity (see Pennington et al., 2016). This is surprising, given that stereotypes are prevalent in real-world environments, and individuals have many flexible social identities that they have chosen to adopt. They also engage in numerous activities that do not involve performance tasks, such as making lifestyle choices and consumer decisions.

\subsection{Consumers and social identity theory}

A small number of studies have applied social identity theory to consumer attitudes and behaviours (e.g., Sowden \& Grimmer, 2009; White \& Argo, 2009; White, Argo, \& Sengupta, 2012; White \& Dahl, 2007). Sowden and Grimmer, for example, analysed interviews conducted with 22 drivers who had recently bought a new car, and found that many saw their choice as a way of maintaining and promoting their social identity. They reported feeling akin to other people who drove the same type of car, and compared themselves favourably to drivers of different types of car, which they would not want to be seen driving. Similarly, 
other studies have revealed how consumers tend to avoid products perceived as being linked

to social groups with which they do not want to be associated (e.g., White \& Argo, 2009;

White \& Dahl, 2007). However, these studies did not examine the specific phenomenon of stereotype threat; they focused only on participants' responses to products felt to be linked with social outgroups that conflicted with their existing social identities, such as an American outgroup for Canadian participants (White \& Dahl, 2007).

\subsection{Study objectives}

The current study therefore seeks to extend the existing research on EV uptake and stereotype threat. It uses a qualitative approach to investigate a psychological barrier to BEV adoption, and focuses on stereotype threat linked to real-world social identities that individuals can choose to adopt or not adopt (in this case, BEV drivers, environmentalists, and technophiles). It also examines naturally occurring stereotype threat over a time period when it becomes salient, as opposed to when it is triggered at a specific time-point in laboratory conditions or questionnaires. This naturally occurring form of stereotype threat is greatly underexplored, yet potentially impactful. The interview data were collected from BEV drivers participating in the UK's Technology Strategy Board (TSB) Ultra Low Carbon Vehicle Demonstrator (ULCVD) programme (see subsection 1.4 for an overview; for full details, see Carroll, Walsh, Burgess, Harris, Mansbridge, King, \& Bunce, 2013). This trial enabled drivers to integrate leased BEVs into their everyday lives and provide extensive feedback on their experiences.

The study focuses on three research questions. As in much qualitative research, these were refined over the course of the analysis (Creswell, 2012). RQ1: To what extent do drivers identify as environmentalists and/or technophiles? This is an important issue, because some studies have shown that individuals are more susceptible to stereotype threat when they identify strongly with the threatened group or domain, but others suggest that strong 
identification may help to overcome harmful consequences (Pennington et al., 2016; Steele et al., 2002). RQ2: Do drivers experience stereotype threat, and if so, what is the nature of the threat? The analysis initially looked for references to any kind of negative stereotypes, and also considered whether the drivers' sense of stereotype threat was activated internally (in their own minds) or externally (by other people). Both internally and externally activated forms of stereotype were included in the analysis. RQ3: What are drivers' defence strategies towards stereotype threat? 'Defence strategies' in this context refers to general attitude and behaviour patterns rather than immediate, individual responses to specific triggers. Shapiro and Neuberg (2007) argue that outcomes of stereotype threat other than decreased performance, such as disengagement or disidentification with the negatively stereotyped domain (Steele et al., 2002), are potentially more significant and likely to have longer-lasting consequences. In addition, they are relevant to a wider range of social groups that are stereotyped on grounds other than performance (Shapiro \& Neuberg, 2007).

\subsection{Context of the study: The TSB ULCVD programme}

This project (2008-2012) was a large-scale ultra low carbon vehicle (ULCV) trial, jointly funded by the TSB (now Innovate UK) and the UK's Office for Low Emission Vehicles. It involved eight consortium groups positioned around England and Scotland, comprising vehicle manufacturers, equipment producers, energy suppliers, university partners, and local authorities. The project was intended to support the development of technologies and markets for ULCVs, assessing drivers' perceptions and concerns in order to identify ways to improve integration and optimise drivers' experiences. It provided a platform for the UK government and consortium group members to evaluate the major facilitators and obstacles facing drivers adopting ULCVs on a long-term basis.

Over $90 \%$ of the 349 ULCVs deployed were BEVs, and drivers were either corporate $(70 \%)$ or private $(30 \%)$. Each consortium group recruited its own participants, handled the 
distribution of BEVs, and provided appropriate training and support. Private drivers (the focus of the current study) responded to advertisements in newspapers, flyers, and websites, and applied for the programme by post or online. Successful applicants were assigned a BEV for periods of 6-12 months, and most paid a monthly lease fee. Data were collected from both the vehicles (through on-board data loggers) and the drivers (through interviews and questionnaires). A research team in the Department of Psychology at Oxford Brookes University collaborated with all consortium groups, designed interviews and questionnaires, and collected data from over 300 private drivers between 2009 and 2012.

\section{Method}

\subsection{Participants}

Participants were 53 private drivers in the TSB ULCVD programme. There were 39 men and 14 women, with an age range of $23-71$ years $(\mathrm{Mean}=46.91, \mathrm{SD}=12.00)$. Additional demographic details were provided by 24 of the 53 drivers; these are presented in Table 1. These demographics are similar to those of the whole TSB dataset, in which drivers were predominantly male, in their mid-40s, white, living with a spouse or partner, and had a university degree (Carroll et al., 2013). Drivers came from three consortium groups, each based in a broad area of England. They were assigned to one of four fully-electric BEV models. This created five driver categories: (i) Consortium group 1, BEV A; (ii) Consortium group 1, BEV B; (iii) Consortium group 1, BEV C; (iv) Consortium group 2, BEV A;

(v) Consortium group 3, BEV D. Car manufacturers in the TSB trial have allowed data to be disseminated to a wider audience provided that specific BEVs are not identified in the results.

The sample size was felt to be optimal for gaining both breadth and depth of understanding. Appropriate inclusion and exclusion criteria were applied. These focused initially on vehicle type. Drivers of four BEV models that were relatively similar in terms of 
201

202

203

204

205

206

207

208

209

210

211

212

213

214

215

216

217

218

219

220

size and performance were included. Drivers of other BEVs were excluded because the vehicles were too different (e.g., vans or sports cars). The criteria then focused on the interview data collected, and drivers who had not completed at least two interviews, including the pre-trial interview, or had given insufficient responses, were excluded. This narrowed down the potential dataset, but two driver categories significantly outweighed the others. These were reduced by a process of random selection, designed to ensure that an appropriate number of female drivers was included for the sample to be regarded as similar to the TSB ULCVD programme private driver group as a whole in terms of gender. The final sample comprised 8-12 drivers in each of the five driver categories (Mean = 10.6).

10

11


221

222

\begin{tabular}{|c|c|c|c|c|c|}
\hline Category & \multicolumn{5}{|c|}{ Response } \\
\hline Ethnic background & \multicolumn{2}{|r|}{ White } & \multicolumn{3}{|c|}{ Mixed } \\
\hline$N=23$ & \multicolumn{2}{|r|}{$96 \%$} & \multicolumn{3}{|c|}{$4 \%$} \\
\hline Marital status & Single & Married & Living with & Divorced/ & Widowed \\
\hline \multirow[t]{2}{*}{$N=24$} & & & partner & separated & \\
\hline & $4 \%$ & $67 \%$ & $13 \%$ & $12 \%$ & $4 \%$ \\
\hline Education level & GCSE/ & A-level/ & Graduate & Post- & Other \\
\hline \multirow[t]{2}{*}{$N=24$} & equivalent & equivalent & & graduate & \\
\hline & $4 \%$ & $29 \%$ & $25 \%$ & $33 \%$ & $8 \%$ \\
\hline On average, how often & \multicolumn{2}{|c|}{ Every day } & \multicolumn{3}{|c|}{ 4-6 days per week } \\
\hline do you drive? & \multicolumn{2}{|r|}{$83 \%$} & \multicolumn{3}{|c|}{$17 \%$} \\
\hline \multicolumn{6}{|l|}{$N=24$} \\
\hline How many hours per & \multicolumn{2}{|c|}{ Range } & Mean & \multicolumn{2}{|r|}{ SD } \\
\hline week do you spend & \multicolumn{2}{|c|}{$2-20 \mathrm{~h}$} & $8.91 \mathrm{~h}$ & \multicolumn{2}{|c|}{$3.97 \mathrm{~h}$} \\
\hline \multicolumn{6}{|l|}{ driving? } \\
\hline$N=22$ & & & & & \\
\hline
\end{tabular}

Table 1

Demographics for a Subset of Participants
223 
+ 1-week (18/53); pre-trial + 3-month (8/53); pre-trial + 1-week + 3-month $(15 / 53) ; 3$-month (12/53). A 'combined' schedule was used for drivers who were interviewed only at the

3-month stage, which included all questions from the pre-trial as well as the 3-month interview. Questions from the pre-trial interview were put into the past tense, and reminded drivers to reflect back on their pre-trial thoughts and feelings. Drivers were not primed to think specifically about stereotypes or negative images, but some questions asked about their perceptions of other people's attitudes (e.g., What have other people's reactions been to you driving your electric car and to the car itself?), and about general barriers facing BEV drivers (e.g., What needs to be overcome for the successful widespread adoption of electric vehicles?). Data were initially analysed by driver category to ensure that no distinct patterns emerged between categories. BEV type, consortium group, and interview time-points were just two variables among many in the project (e.g., driver age, gender, occupation, and location), and this study focuses on findings relevant to the wider BEV market rather than to specific BEVs. All relevant information provided by drivers was analysed, regardless of the questions used to elicit it.

The interviews were one-on-one and conducted over the telephone. The majority lasted between 30-90 minutes. The semi-structured schedules were designed to cover a wide range of topics, varying from the practical aspects of BEV usage to drivers' deeper, psychological engagements with their cars. The main topics were: drivers' motivations and expectations of the trial; perceived barriers and facilitators to BEV uptake; experiences of charging, driving, and dealing with limited range; general and specific adaptation experiences; challenges encountered and coping strategies used; other people's attitudes towards BEVs; and image and identity issues. The interviewer prompted drivers to give specific examples in response to the questions, and encouraged them to elaborate on their initial answers with follow-up 
253

254

255

256

257

258

259

260

261

262

263

264

265

266

267

268

269

270

271

272

273

274

275

276

277

probes (Smith \& Osborn, 2008). Interviews were transcribed verbatim, including all nonverbal utterances (e.g., laughing, sighing) and vocal distractors (e.g., ums, ers).

\subsection{Data analysis}

Transcripts were analysed in accordance with the guidelines for thematic analysis (Braun

\& Clarke, 2006, 2012). The current study evolved out of a broader investigation into issues of image and identity related to BEVs, for which inductive (data-driven) analysis prioritised the drivers' perspectives and identified 'undesirable stereotypes of BEV drivers' as a potential theme. When the initial, broad research questions for this study were developed (RQ1: Do drivers feel that they are being stereotyped, and if so, in what way?; RQ2: What are drivers' reactions to stereotypes?) the process of thematic analysis was conducted afresh. It shifted from an inductive to a deductive (theory-driven) approach when the main themes had been established. The research questions were then refined and the theoretical framework of stereotype threat was selected and applied (Braun \& Clarke, 2006, 2012).

Early readings of the transcripts focused on pinpointing meaningful features of the data which were firmly grounded in the drivers' statements, as this helped to ensure that themes did not simply evolve out of extraneous preconceptions. The transcript annotations were then coded and collated across the entire dataset, resulting in a list of semantic-level codes. These codes were sorted and collated into potential themes and subthemes, a process which involved clustering and re-clustering of codes in order to reflect clear and meaningful patterns across the data. Potential themes and subthemes were reviewed and revised until they met Patton's (1990) dual criteria of 'internal homogeneity' (meaningful coherence of data within a theme) and 'external heterogeneity' (clear distinctions between each theme). This phase focused on the latent, psychological meanings beneath the surface of the data. Due to the subtleties and ambiguities of some of the drivers' statements (e.g., emotions communicated, use of irony), the first author listened to interview recordings where necessary 
to assess vocal nuances (e.g., tone, pitch, tempo, volume) and interpret the drivers' intended and implied meanings. The selected themes and subthemes were then named and refined further, in order to ensure that they captured the essence of both the data and the overall narrative. This phase drew on in-depth, deductive analysis, and related data back to existing literature and the theoretical approach.

\section{Results and Discussion}

This section comprises two main themes: Environmentalist identities and Technophile identities. The initial, inductive analysis looked for references to any kind of negative stereotypes, such as foolish over-spenders (Heffner, 2007) or 'sensible and boring' people with slow-moving lifestyles (Graham-Rowe et al., 2012, p. 149), but all quotes directly relating to stereotypes of social groups, as opposed to individual personality characteristics, clustered into the above two categories. This suggests that while other stereotypes may have existed, the environmentalist and technophile stereotypes were the main ones to affect the drivers. Quantitative data in the form of numbers and percentages are presented to provide clarity, expose complexities, and enable comparison within the participant sample (see Maxwell, 2010, for discussion of advantageous use of numbers in qualitative research). They are not intended to be generalised beyond the participant sample. Numerical identifiers were assigned to drivers in order to maintain anonymity.

\subsection{Environmentalist identities}

\subsubsection{Did drivers identify as environmentalists?}

At pre-trial, almost all drivers $(51 / 53,96 \%)$ agreed that it was important to power cars in a way that limited environmental damage. However, in response to open-ended pre-trial questions asking them to indicate the most important reasons for participating in the trial, 
only 16 drivers $(30 \%)$ reported that protecting the environment had been a primary $(6 / 53$, $11 \%)$ or subsidiary $(10 / 53,19 \%)$ personal motivating factor. Analysis of the whole interview dataset revealed that just 14 drivers (26\%) made reference at any point to the 'green' image of BEVs interacting with their individual identities in a positive way, either by matching or enhancing their existing self-images. Three of these drivers $(6 \%)$ implied that they perceived themselves to be part of a 'green' social group, but this sense of support was undermined for one driver who stated that even his pro-environmental friends viewed adoption of a BEV as being a step too far. Together, these findings suggest that although the majority of drivers liked to perceive themselves as being environmentally friendly to some extent, they did not identify strongly as environmentalists.

\subsubsection{Stereotypes of environmentalists}

Shifting from the drivers' own points of view to their assumptions and beliefs about other people's perceptions, over half $(27 / 53,51 \%)$ referred at some point in their interviews to a form of undesirable environmentalist stereotype attached to the BEVs. Two opposing categories emerged: the Low-status 'green' identity and the High-status 'green' identity.

Three drivers $(6 \%)$ made reference to both categories, implying that different individuals saw BEV drivers in different ways.

\section{Low-status environmentalists}

Twenty of the 53 drivers (38\%) made reference to a low-status environmentalist stereotype. Most of their comments were relatively light-hearted, but nevertheless carried the impression that other people could judge and treat them as belonging to a stigmatised social group. They felt that BEV adopters could be perceived by others as deviant 'tree-huggers' (P17), ‘eco-warriors' (P15, P22, P46), ‘eco-freaks' (P11), and 'weird, freaky nutters' (P40) who defied established social norms and embraced alternative 'hippy and green' ones (P43): 
I think people see you as a tree hugger. . . . There's a bit of a difference between an electric car and a Porsche, they're opposite ends of the [status] spectrum. (P17)

I suppose what's happened is that others - colleagues, neighbours, friends - have seen me drive this car and their perception of me may have changed, they may think he's an eco-warrior. (P22)

Nineteen of these 20 drivers spoke about how they imagined other people to view them, as opposed to referring to actual encounters. Despite the fact that the majority of drivers did not identify strongly as environmentalists, the act of simply driving a BEV seemed to trigger this well-established stereotype in their minds.

The images evoked by the drivers were linked to impressions of radicalism, eccentricity, and self-sacrificing frugality. This is in line with research findings that indicate how such environmentalist stereotypes can be used by the public to alienate and denigrate people who are felt to present a challenge to existing attitudes and behaviours (Hutchings, 2005; Jorgensen, 2011). These stereotypes could function to reduce public cognitive dissonance over pro-environmental behaviour by making BEV adopters look foolish and out of touch. In addition, they may have appeared particularly absurd in the BEV context, as the idea of clinging to trees and embracing an outdated 'hippy' mindset contrasts vividly with the image of an early adopter of new vehicle technology. Only one driver reported encountering any comments related to low-status environmentalists:

[Friends and family think] Oh [him] and his bloody electric cars, stuff like that! [Laughter] You and your holier-than-thou go-kart, you're one of those eco-people! That sort of thing. So I've had a bit of that. (P40)

The stereotype seemed to operate to a large extent in the drivers' imaginations, influencing the ways in which they perceived, constructed, and attempted to project their own identities. 


\section{High-status environmentalists}

On the other side of the status spectrum, 10 drivers (19\%) indicated that BEVs were associated with a high-status environmentalist stereotype. None of these drivers reported realworld encounters, so the stereotypes appeared to exist in their own minds. They were often linked to the adoption of EVs by film stars, but this connection with Hollywood was felt to be 'uncomfortable' as it implied that the BEV drivers were simply trying to show off their altruism or copy US celebrities:

I think there's a kind of a . . . slightly uncomfortable feeling of 'holier-than-thou'.... Like Hollywood stars driving [HEVs] . . there is a little bit of wearing your environmental heart on your sleeve. (P53)

There may be a bit of snobbery attached to it that says ... "I am very environmental, very switched on”, oh, a new term I've heard - “environmental bling”. [Laughter] (P22)

These drivers seemed to fear that they might inadvertently confirm the sanctimonious stereotypes in their own eyes, as well as in the eyes of other people. They also implied that mainstream consumers would dismiss BEVs as a fashion statement or a passing fad, rather than a viable, long-term transport option. They felt the high-status 'green' image to carry an impression of pretentiousness and hypocrisy which they wanted to avoid:

Judging by the use of hybrid vehicles by the Hollywood set . . I think a lot of these actors and actresses like to improve their image by either pretending or actually doing good deeds. (P45)

I bet you those people that say, "Oh yes it shows that we're fantastically environmentally friendly", I bet you they take flights abroad frequently. (P43) 


\subsubsection{Drivers' defence strategies for environmentalist stereotypes}

In the face of these two environmentalist stereotypes, the drivers tended to downplay their environmental concerns. Despite the lack of real-world encounters, many appeared to have internalised the stereotypes to the extent that they felt it necessary to create a defensive understanding of who they were in relation to their BEVs. When they expressed proenvironmental views, they were careful to make moderate and sensible statements such as, 'I'm fairly green' (P46) or 'We quite like to be green' (P26), which differed from the passionate assertions made by many US HEV drivers who liked to wholeheartedly 'embrace the image of environmental stewardship' (Heffner, Kurani, \& Turrentine, 2005, p. 5). Seven drivers in the current study (13\%) defined their 'green' identities clearly in terms of what they were not, wavering between endorsing pro-environmental attitudes and rejecting the radical 'environmentalist' label:

I'm not a, you know, big sort of green environmentalist . . I don't wear that big badge, but I do my bit, you know, recycle . . . I'm probably a mediocre greenie rather than a ... "I'm out to save the planet". (P32)

I'm not an environmentalist . . . but . . . if you were an environmentalist, you'd think you could sleep at night knowing that you're not polluting from carbon emissions. (P24)

I asked for [the BEV] because I thought it was a great concept . . . not because I'm an environmental egghead, just that I think it's a good solution. (P16)

A further three drivers $(6 \%)$ indicated that EVs were only considered a high-status environmentalist symbol by people who identified with this particular social group and had positive images reflected back to them by other group members. They did not seem to know 
396

397

any people like this, but nevertheless made clear that they did not regard themselves as belonging to this category:

I suppose you could argue, yes, I'm an environmentalist, therefore I've got an electric car. So yes, I think for some people they can be a status symbol. (P47)

I think [BEVs] probably are [a status symbol] to some people. . . . That is a lot of money to park one on your driveway and say, "Look at me, I'm being really green". I suppose for eco-warriors with massive budgets they are a bit of a status symbol. (P46)

Two drivers (4\%) said that using a BEV was not a fixed or permanent environmental commitment, but an identity that could be shrugged off if necessary. In other words, the stereotypes appeared to prompt them to identify less strongly as BEV drivers:

I'm not doing it, it's not a religion, it's because I think it's the right thing to do, but if it turns out to be the wrong thing to do then I'll stop doing it. (P26)

If the car is just a toy for an environmentalist to do their little one-mile journey in every day then fine, that's where it'll be, and I can go and buy my high performance sports car. (P43)

The stereotype threat literature would define these psychological defence strategies as 'disengagement' (a short-term, reversible response) or 'disidentification' (a long-term, chronic response that involves a reconceptualisation of the self and of one's values) (Steele, 1997; Steele et al., 2002). They operate on an individualist level, in that the person who experiences or anticipates stereotype threat acts to reduce the negative effects by dissociating themselves from the domain in which the stereotype is relevant, or from the group at which the stereotype is targeted (Pronin, Steele, \& Ross, 2004; Steele et al., 2002). In the case of the BEV drivers, they indicated that the domain of caring about the environment was not overly 
important to them, or that they could even reject their whole BEV driver group membership.

One driver mentioned the possibility of engaging in highly counter-stereotypic behaviours by switching to a fuel-guzzling ICE sports car, reflecting the actions of a HEV driver who reported how he chose to drive at very high speeds to avoid being labelled a " tree-hugger" driving an econo-box' (Heffner, 2007, p. 175), and the hypermasculine, risk-taking behaviours described by male drivers who felt threatened by a feminine image attached to their ICE Porsche model (Avery, 2012).

Although these disengagement and disidentification strategies work to protect the individual's self-esteem to some extent, they can be detrimental in other ways as they may cause internal conflict and limit opportunities for self-development (Pronin et al., 2004; Steele et al., 2002). In the BEV context, it would obviously be problematic for both individuals and society at large if BEV drivers felt obliged to curb their pro-environmental attitudes and behaviours, engage in counterstereotypic actions, and in the light of a largely self-activated stereotype, persuade themselves and others to see protecting the environment as a relatively insignificant action.

\subsection{Technophile identities.}

\subsubsection{Did drivers identify as technophiles?}

The term 'technophile' is defined in this study as 'a person who is interested in modern technology and enjoys using it' (Cambridge Dictionary, n.d). In response to the open-ended pre-trial questions, 24 drivers (45\%) indicated that their interest in innovative technology had been a primary $(19 / 53,36 \%)$ or subsidiary $(5 / 53,9 \%)$ personal motivating factor for participating in the trial. This showed that more drivers were motivated by an interest in innovative technology than by protecting the environment $(16 / 53,30 \% ; 11 \%$ primary, $19 \%$ subsidiary). Analysis of the whole dataset revealed that 36 drivers (68\%) made clear reference at some point to the innovative technology image of BEVs interacting with their 
individual identities in a positive way, either by matching or enhancing their existing selfimages. Again, this was a much higher proportion than the 14 drivers $(26 \%)$ who made clear reference to this for the 'green' image. Eight drivers (15\%) made clear reference to both the innovative technology and 'green' images interacting with their identities in a positive way, while 11 drivers $(21 \%)$ did not make clear reference to either.

Twenty-four (45\%) of the 36 drivers who identified as technophiles referred to acquiring a new form of social identity, explaining how they felt 'involved in' or 'part of' something special and unique and saw themselves as 'one of the privileged few' (P49). This stemmed partly from the TSB trial itself, but only two drivers (4\%) made explicit reference to communicating with other participants. The majority referred primarily to a more abstract and psychological sense of belonging to a group of BEV drivers who were helping to shape the future:

I felt like a big part of it to be honest, and obviously speaking to [the interviewer] and then answering the questionnaires ... and the Facebook group [for trial participants] as well, I think helped a lot to keep everyone together and what everyone experienced then, so yeah there was a real sort of community feeling to it I thought, it was good. (P41)

It's being part of evolving technology really, I mean, I think it's the way forward and this is a good opportunity to be a part of it. ... We're going to be . . involved in something in the future so, you know, it's great to be a part of it really at the outset. (P47)

The emphasis on ground-breaking, future-shaping technology allowed these drivers to distinguish themselves from more traditional technophiles (including ICE car lovers, often described by the BEV drivers as 'petrolheads') who were generally resistant to BEVs. 


\subsubsection{Stereotypes of technophiles}

Shifting from the drivers' own points of view to their beliefs about other people's perceptions, 18 drivers (34\%) referred at some point in their interviews to a form of undesirable technophile stereotype attached to the BEVs. Fifteen of these drivers (28\%) had also referred to a form of undesirable environmentalist stereotype. The technophile stereotypes fell into a single category which generally carried a low-status association. The drivers in this category felt that other people could judge and treat them as socially deviant, foolish, and risk-taking adopters of a peculiar form of technology. Six drivers (11\%) reported direct contact with people who held these opinions:

A lot of people that I spoke to about being part of the trial have all been . . . they just had a good laugh about [me] having an electric car, "Oh it's going to be like a milk float or a dodgems car", you know ... they were all sort of quite detrimental of it and it was a bit of a joke. (P07)

[Some people] think it's mad . . . because of the lack of range, and they may laugh about the fact that I might find myself halfway down some sort of A road, standing on the side, scratching my head because the battery's expired. (P50)

A further four (8\%) mentioned encountering a few 'jokes' and 'sniggers' from colleagues and friends. The remaining eight drivers $(15 \%)$ spoke about how they imagined other people to view them, with no reference to actual encounters.

The technophile stereotypes were sometimes linked to the image of outdated and underpowered vehicles, but sometimes to the image of radically futuristic machines. Both of these images carried the impression of impractical technology that any 'sensible person' (P01) would view in a disparaging way. The drivers felt that they could be seen as a bit 'daft' 
491 (P01, P07), 'silly' (P01, P05), 'dotty' (P26), 'stupid' (P10), or on a more humorous level,

492

493

494

495

496

497

498

499

500

501

502

503

504

505

506

507

508

509

510

511

512

513

'mad' (P01, P04, P17, P50):

I think [friends and family are] withholding judgement [on BEV technology], basically. They think it's probably us being a bit dotty. (P26)

A further four drivers used the words 'geek' (P39), 'geeky' (P31, P46), or 'nerd' (P34) in a relatively light-hearted way, evoking the stereotype of 'someone that's in early with technology, does it really work, all that stuff, so a bit obsessive' (P40):

[My children] thought I was being a geek being on this trial, and my younger children pretty well said, "I'm not coming out with you in that, Dad, I'm going to be so embarrassed", and so they were fairly negative about it. (P34)

Six male drivers (11\%) thought that some people perceived 'geeky' BEV drivers as effeminate, favouring quirky technology over high-powered ICE cars:

I didn't worry that it undermined my identity as a male or whatever [but] I think there would be a lot of men who wouldn't touch it with a barge pole for that very reason. ... Cars are such a macho thing for a vast majority of the driving public. . . I think a lot of blokes are cynical . . . they'll just argue with you and tell you it's a complete rip off and accuse you of being stupid. (P10)

Men are a bit like, "Hey, come on ... I need a flash car, it's an extension of my personality" ... [Laughter] . . I just think when a woman sees it she'll just think... $H m m m$... A woman looking at you and a woman thinking What a plonker are two completely different things. (P43)

This suggests that the technophile stereotype could be considered more detrimental by male drivers, especially those who see ICE cars as a way of projecting the traditional image of 
514

515

516

517

518

519

520

521

522

523

524

525

526

527

528

529

530

531

532

533

534

535

strong, prestigious, and desirable masculinity (Avery, 2012). Avery observed that in Western

culture, 'most men manage their masculinity through consumption to ward off fears that

others will see them as effeminate', and research suggests that using 'feminine' brands carries greater stigma for men than using 'masculine' brands does for women (p. 323). Overall, these technophile stereotypes shared similar characteristics to the environmentalist ones, communicating the idea that BEV drivers belonged to a minority social group that warranted a certain amount of derision.

\subsubsection{Drivers' defence strategies for technophile stereotypes}

In contrast to their defence strategies for the environmentalist stereotypes, drivers tended to display more positive approaches in the face of imagining or encountering technophile stereotypes. They often conceptualised other people's views as an enjoyable challenge:

Oh, the major challenge without a doubt is being good humoured when people are rude to me! [Laughter] . . . The biggest challenge is going to be getting used to people's reactions. ... But that's fun, that's fun. (P01)

This appeared to enhance their self-esteem, allowing them to perceive themselves as strong and resilient. Many drivers reported that with some effort and resilience, they were able to transform people's views of BEVs as impractical or embarrassing technology over the course of the trial:

[My children are now] 100\% converted. . . I didn't let that embarrassment put me off, and so I did the school run from time to time.... When their friends started saying, "Well, it's quite cool", they changed their opinion greatly. ... The view of the family has really, really changed. (P34) 
They also indicated that they could reject the stereotype, as opposed to the domain or identity to which it was associated. Five drivers (9\%) used a certain degree of "self-effacing humor that confesses to, but spoofs, the allegation in the stereotype' (Steele et al, 2002, p. 434):

I think the reaction ... at the [sports club] was, "He really has lost it!" The general feeling on electric cars, in the circle that I'm in, is that they're not viable yet.... [Friends] think that I shall be totally mad! They say, "What on earth do you think you're doing?" They'll go home and say to their wives, "You won't believe what he's done now!" (P01)

I've had the odd look, generally from very large SUV [sports utility vehicle] drivers, the head shake, they do the head shake, and I'm trying to understand what that emotion is but they just look at it and go, "Uchhh oh", as if they saw me wearing a dress! [Laughter] "Oh, there's a bloke in a dress, oh!” (P40)

By laughingly imagining themselves being viewed as completely 'mad' or 'a bloke in a dress', they exaggerated the stereotype to the extent that it became implausible and could even be considered absurd. This approach carries the potential to reflect the negativity back onto the stereotype holders by implying that they are the foolish people with a poor grasp of reality.

Other drivers went a step further and indicated that they had psychologically assigned non-BEV drivers to an inferior social group, applying a strategy that social identity theory would define as ‘social competition' (Tajfel \& Turner, 1979, 1986). Drawing on their new sense of social identity, they developed a sense of ingroup 'positive distinctiveness' (Tajfel \& Turner, 1979) and conceptualised ingroup members as more confident and forward-thinking technology users than outgroup members. They saw themselves as being at the vanguard of a 
559

560

561

562

563

564

565

566

567

568

569

570

571

572

573

574

575

576

577

578

579

580

global technology revolution, which distinguished them from mainstream consumers and traditional technophiles who relied on technology rooted in the past:

I think there are lots of people out there who would be afraid of the change and couldn't cope with that kind of open-mindedness and future-facing concept. (P15)

This allowed them to see themselves as distinctly superior to non-BEV drivers:

It's kind of cool to be involved in something cutting-edge, early adopter and all that. ... There is a little bit of fun in saying, "Look what I've got, you haven't got one of these, hahaha!" (P50)

I feel quite sorry for poor mortals driving cars with engines in. (P11)

These drivers appeared to have engaged in complex internal dialogue, whereby they selfactivated the negative stereotype, imagined how other people might see them, reconceptualised their sense of identity, and went on to envisage defensive responses to the imagined stereotypes. These responses were not individualist but group-level strategies, which caused the drivers to associate more strongly with their ingroup, and try to produce real social change in the hierarchy of BEV driver/non-BEV driver groups. Their ingroup was not a closed group, however, and the drivers did not display antagonism towards outgroup members. They typically saw themselves as 'pioneers' (P14, P32) and 'one of the first' (P09, P10, P15), implying that they were taking the lead and that the mainstream market would soon start to follow their example. Many drivers embraced the real-world role of being 'ambassadors' (P11, P34, P51) and 'advocates' (P07, P15) for the BEVs, promoting the benefits of the cars as much as possible and transforming the image of strange and unviable gimmicks into that of exciting and efficient technology. These drivers believed that BEVs 
581

582

583

584

585

586

587

588

589

590

591

592

593

594

595

596

597

598

599

600

601

602

603

604

605

would become the norm in the future, leaving non-BEV drivers as a devalued, outdated, and minority social group.

\section{General Discussion}

The UK's TSB ULCVD programme was the world's largest multi-vehicle, multi-location EV field trial, launched as a collaborative project with the specific intention of determining ways to improve the likelihood of successful EV integration into the national fleet. The current study's application of the well-established theory of stereotype threat to this realworld test of innovative technological change has helped to elucidate potential obstacles and facilitators to that integration. The findings revealed that the majority of drivers $(30 / 53,57 \%)$ did appear to encounter stereotype threat, either through direct contact with other people $(11 / 53,21 \%)$ or, more frequently, in their own imaginations like 'the threat of a snake loose in the house' (Steele et al., 2002, p. 389). Despite their own positive views of BEVs and BEV drivers, the act of simply participating in the trial seemed to trigger the stereotypes in many of the drivers' minds, leading them to question their own identities and to anticipate or assume that other people would see them as belonging to a stigmatised social group. This suggests that stereotype threat poses a significant problem for BEV uptake. Although the large majority of drivers reported that they enjoyed the experience of driving a BEV and appeared to perceive the positive aspects of the BEVs as outweighing the negative stereotypes, it is unlikely that this would be the case for mainstream consumers who generally hold ambivalent or sceptical views of the vehicles (Burgess et al., 2013; GrahamRowe et al., 2012; TfL, 2016), and may see them as incongruent with their own personalities (Skippon, Kinnear, Lloyd, \& Stannard, 2016).

Despite the fact that fewer drivers indicated identification as environmentalists than as technophiles, more drivers made reference to environmentalist stereotypes $(27 / 53,51 \%)$ than 
technophile stereotypes $(18 / 53,34 \%)$. In addition, only one driver reported actual encounters with negative perceptions of environmentalist BEV drivers, compared to the 10 drivers who reported negative comments, jokes, or sniggers about technophile BEV drivers. This contrasts with other stereotype threat research, which has found individuals to be more susceptible to stereotype threat when they identify strongly with the threatened group or domain (see Pennington et al., 2016; Steele et al., 2002). What could account for this difference? One possible explanation is that the current study examined a new identity acquired by the participants (i.e., BEV driver), as opposed to a pre-existing identity (e.g., gender or ethnicity, as examined by most existing stereotype threat studies). In the consumer context, it is perhaps the case that individuals who adopt a new product that is linked to both a desirable new identity and a negative stereotype feel more threatened by the stereotype if they do not identify strongly with the targeted group. In other words, the BEV drivers who did not identify as environmentalists may have found it more incongruous and off-putting to suddenly realise that they might be seen as 'tree-huggers' or 'eco-warriors with massive budgets'. This suggests that stereotype threat operates in different ways in different domains (i.e., performance domains and consumer decision-making domains), and would benefit from more research in the consumer field.

The drivers also appeared to use different defence strategies towards the environmentalist and technophile stereotypes. In the context of the former, they generally took the individualist approach of psychologically dissociating themselves from the undesirable groups by downplaying their environmental concern, or reminding themselves that they could discard their whole BEV driver identity if necessary. In the context of the latter, they generally took the group-level approach of 'social competition', identifying more strongly with their BEV driver ingroup and considering it to be superior to their non-BEV driver outgroup. This ingroup was a relatively abstract and psychological construct, as only two drivers made 
631

632

633

634

635

636

637

638

639

640

641

642

643

644

645

646

647

648

649

650

651

652

653

654

655

explicit reference to communicating with other trial participants, but it seemed to offer a strong source of internal resilience which many drivers subsequently translated into realworld action by promoting their BEVs to members of the public.

What were the reasons for these different strategies? The fact that a larger number of drivers identified as technophiles implies that they were perhaps more willing to invest effort into confronting and transforming the 'geeky' stereotypes, both in their own minds and in those of other people. They might have seen environmentalist stereotypes as more culturally embedded and harder to contest, whereas technophile stereotypes are potentially more flexible in an age that has seen an explosive uptake of consumer technology around the world, with people becoming highly dependent on products such as computers and mobile phones. The images of the BEVs may also have played a role; while the 'green' image was based on abstract environmental credentials that were difficult to prove, the drivers seemed to find it relatively easy to overcome images of BEVs as unviable technology by exposing people to the cars and demonstrating their advantages.

$$
\text { However, the main reason appeared to be the emergence of a desirable form of social }
$$
identity for innovative technology adopters, which was mentioned by 24 drivers (45\%). In contrast, only three drivers $(6 \%)$ reported being involved in a 'green' social community. Feeling that they were part of a pioneering technology adopter team was a new form of social identity, not dependent on prior technological expertise; simply by adopting a BEV, the drivers were able to gain the psychological sense of belonging to a unique and trailblazing group. This put them in a position where they could respond to the stereotype threat by setting out to alter the relative positions of the BEV driver/non-BEV driver groups, as opposed to using self-protective individualist strategies (Tajfel \& Turner, 1979, 1986). While this 'social competition' tactic has been discussed extensively in the domain of social identity theory (Tajfel \& Turner, 1979, 1986), stereotype threat research which has looked beyond 
immediate performance outcomes has focused almost exclusively on self-limiting, individualist strategies such as disengagement and disidentification (Aronson, 2002; Shapiro \& Neuberg, 2007; Steele at al., 2002).

With regard to implications for stakeholders engaged in the promotion of BEVs, this study extended existing research which has identified negative images of EV drivers (Burgess et al., 2013; Graham-Rowe et al., 2012; Heffner, 2007); by applying a theoretical framework, it exposed how these were not simply images directed at individuals but more powerful stereotypes targeting devalued social groups. The findings also suggested that a possible way to counter this problem would be to advocate the image of an influential and desirable innovative technology adopter group that would appeal to forward-thinking consumers. The sense of being adventurous trendsetters at the forefront of a global change might also enable such drivers to conceptualise other psychological barriers to BEV usage, such as apprehension about recharging routines (Bunce, Harris, \& Burgess, 2014) and 'range anxiety' caused by limited driving range (Rauh, Franke, \& Krems, 2015), as interesting, conquerable challenges instead of intimidating responsibilities.

Potential real-world actions to promote the image of a desirable, pioneering BEV driver group could involve a variety of advertising platforms, including the media, social media, films, and television programmes. Support and publicity for BEV hire clubs, BEV enthusiast clubs, and online communities could encourage BEV drivers and potential adopters to exchange information, share experiences, and give and receive advice (see Le Vine, 2012, for extensive discussion of different kinds of ICE car hire clubs in the UK). An accessible rather than exclusive and elitist group image would be essential, and ventures such as BEV hire club schemes could play a key role in allowing consumers to experience BEVs in everyday situations without committing themselves to purchase. Personal contact with BEVs has also been shown to be highly effective in transforming mainstream consumers' negative 
681

682

683

684

685

686

687

688

689

690

691

692

693

694

695

696

697

698

699

700

701

702

703

704

705

stereotypes of the vehicles as strange and unviable into exciting and practical technology (Burgess et al., 2013).

Alongside 'normalising' the image of BEVs and their drivers, however, an element of distinction could also be beneficial to counter the stereotypes of an inferior social group. In public carparks, for example, BEV drivers could be offered charging points in parking spaces that were slightly larger than those for ICE cars, and distinguished by features such as attractive paintwork and overhead cover in outdoor sites. Additional token indicators of superiority could also be effective; as observed by a paper examining how airlines constructed a sense of social prestige for high-class passengers, small items such as personalised luggage labels or membership cards indicating access to a social group with a desirable name (e.g., 'Club Premier' or 'Gold Circle') are able to generate a strong sense of distinctive social identity (Thurlow \& Jaworski, 2006). In the BEV context, these items might take the form of public charging cards offering a range of 'perks', 'privileges', and 'rewards' (Thurlow \& Jaworski, 2006, p. 118), such as free hot beverages at participating service stations and retail stores. These would not place ICE drivers at a disadvantage (as would more radical strategies such as converting large areas of carparks to BEV-only parking spaces), but could allow BEV drivers to view themselves as being in a position of luxury while waiting for their vehicles to recharge, as opposed to a position of self-sacrificing inconvenience.

\section{Conclusions}

This research drew on data collected as part of a much larger real-world project, and some limitations should be taken into consideration. First, the interview schedules focused on breadth rather than depth, and only a small proportion of questions specifically addressed issues of image and identity. This was beneficial in some ways as the drivers revealed the 
importance of undesirable stereotypes on an inductive level, but it also meant that drivers' thoughts and feelings may not have been fully captured. It would be helpful, for example, to consistently ask drivers how prevalent they thought the stereotypes to be, and how closely related they felt to the perceived stereotype holders (e.g., were they referring to a few strangers in the street, or to most of their close friends and family?). This could affect their perceptions of how entrenched the stereotypes were, and the ways in which they felt able to respond.

Second, the nature of the TSB ULCVD programme made face-to-face interviews unviable due to the large number of participants and multiple locations, but researchers of future studies could interview BEV drivers in person to form a stronger relationship of trust, build rapport, and establish the conversational mode that encourages deep and reflective responses (Rubin \& Rubin, 2012).

Third, this research offered insight into the views of a unique sample of BEV drivers, and the results were not intended to be representative of the UK mainstream market. Further research could determine the extent to which the findings may be generalised to mainstream consumers. However, the drivers could be considered 'early adopters' in a broad sense (as observed by Skippon et al., 2016, the term 'early adopters' in EV research tends to be used less precisely than by Rogers, 2003). It is important to assess the perspectives of this consumer segment, which can powerfully influence the opinions of mainstream consumers and help to swing the market one way or the other (Rogers, 2003). The fact that the majority of drivers were male, white, and in their mid-40s was interesting in its own right, and future studies could examine why so many early BEV adopters shared these demographic profiles, and whether factors such as gender, ethnicity, and age influence drivers' attitudes and behaviours towards stereotype threat.

Fourth, it must be taken into account that the findings are culturally and temporally 
731

732

733

734

735

736

737

738

739

740

741

742

743

situated. Different stereotypes may exist in different global cultures, and stereotypes may

shift over time as BEV uptake increases. This shift could be positive, insofar as

environmentalist and technophile stereotypes might disappear as BEVs become normalised,

but it could also be negative if new stereotypes emerge (e.g., 'space hoggers' or 'pavement

blockers'; see Laker, 2018, for details of the controversy over how charging points are

obstructing pedestrians in some areas of London). It is also important to note that the findings

were to some extent unique to the time period of the trial, when BEVs were in their earlier stages of development and differed in some ways (e.g., size and maximum speed) to the wide range of models currently available in the UK. Nevertheless, the main practical barriers of high upfront purchase costs, limited driving range, and insufficient public charging infrastructure still exist, and given that $99.43 \%$ of non-commercial cars registered in the UK in the first 6 months of 2018 were not BEVs (SMMT, 2018b), it is clear that the market still has a long way to go.

To conclude, this study offered new insight into BEV drivers' experiences at a time when BEVs face a critical turning point for mainstream adoption. By addressing the phenomenon of stereotype threat outside the laboratory, it also advanced the scope of research in this particular domain of social psychology, both in terms of the nature of the social context and the nature of the identity under 'threat'. Ongoing investigation could help to shape innovative ways of addressing psychological barriers and facilitators for uptake of novel products in a world increasingly committed to tackling pollution and climate change.

(1)

2 
756 We would like to thank Innovate UK (formerly the Technology Strategy Board) for

757 supporting this research with funding. We would also like to express appreciation to the

758 drivers, car manufacturers, energy suppliers, and other consortium group members who

759 participated in the Ultra Low Carbon Vehicle Demonstrator programme, and to Dr Sarah

760 Mansbridge and Dr Elisa Lewis for their research assistance.

761

762 Funding sources

763 This work was supported by the Technology Strategy Board (now renamed Innovate UK),

764 and Oxford Brookes University, UK. There were no conflicts of interest at any stage of this research, and the outcomes were not influenced in any way by sources of support. 
775

776

777

778

779

780

781

782

783

784

785

786

787

788

789

790

791

792

793

794

795

796

\section{References}

Abdou, C. M., \& Fingerhut, A. W. (2014). Stereotype threat among Black and White women in health care settings. Cultural Diversity and Ethnic Minority Psychology, 20(3), 316-323. doi:10.1037/a0036946

Appleyard, B. (2009, November 29). This mountain range in Bolivia was once covered in snow. Now it isn't. What do its barren slopes tell us? The Sunday Times Magazine, pp. 10-14.

Aronson, J. (2002). Stereotype threat: Contending and coping with unnerving expectations. In J. Aronson (Ed.), Improving academic achievement: Impact of psychological factors on education (pp. 279-301). London: Academic Press.

Avery, J. (2012). Defending the markers of masculinity: Consumer resistance to brand gender-bending. International Journal of Research in Marketing, 29, 322-336. doi:10.1016/j.ijresmar.2012.04.005

Axsen, J., \& Kurani, K. S. (2013). Developing sustainability-oriented values: Insights from households in a trial of plug-in hybrid electric vehicles. Global Environmental Change, 23(1), 70-80. doi:10.1016/j.gloenvcha.2012.08.002

Belk, R. W. (2004). Men and their machines. In B. E. Kahn \& M. F. Luce (Eds.), NA Advances in consumer research, Vol. 31 (pp. 273-278). Valdosta, GA: Association for Consumer Research.

Bennett, R., \& Vijaygopal, R. (2018). Consumer attitudes towards electric vehicles: Effects of product user stereotypes and self-image congruence. European Journal of Marketing, 52(3/4), 499-527. doi:10.1108/EJM-09-2016-0538 
797

798

799

800

801

802

803

804

805

806

807

808

809

810

811

812

813

814

815

816

817

818

819

Braun, V., \& Clarke, V. (2006). Using thematic analysis in psychology. Qualitative Research in Psychology, 3, 77-101. doi:10.1191/1478088706qp063oa

Braun, V. \& Clarke, V. (2012). Thematic analysis. In H. Cooper, P. M. Camic, D. L. Long, A. T. Panter, D. Rindskopf, \& K. J. Sher (Eds.), APA handbook of research methods in psychology, Vol. 2 (pp. 57-71). Washington, DC: American Psychological Association.

Bunce, L., Harris, M., \& Burgess, M. (2014). Charge up then charge out? Drivers' perceptions and experiences of electric vehicles in the UK. Transportation Research Part A: Policy and Practice, 59, 278-287. doi:10.1016/j.tra.2013.12.001

Burgess, M., King, N., Harris, M., and Lewis, E. (2013). Electric vehicle drivers' reported interactions with the public: Driving stereotype change? Transportation Research Part F, 17, 33-34. doi:10.1016/j.trf.2012.09.003

Carr, P. B., \& Steele, C. M. (2010). Stereotype threat affects financial decision making. Psychological Science, 21(10), 1411-1416. doi:10.1177/0956797610384146

Carroll, S., Walsh, C., Burgess, M., Harris, M., Mansbridge, S., King, N., \& Bunce, L. (2013, September). The Ultra Low Carbon Vehicle Demonstrator programme final report: Assessing the viability of EVS in daily life. http://www.cenex.co.uk/wpcontent/uploads/2014/02/ULCV-Demonstrator-final-report.pdf Accessed 10 July 2018.

Creswell, J. W. (2012). Qualitative inquiry and research design: Choosing among five approaches (3rd ed.). London: Sage.

Davies, P. G., Spencer, S. J., \& Steele, C. M. (2005). Clearing the air: Identity safety moderates the effects of stereotype threat on women's leadership aspirations. Journal 
of Personality and Social Psychology, 88(2), 276-287. doi:10.1037/0022-3514.88.2.276

Department for Environment, Food and Rural Affairs, \& Department for Transport. (2017, July). UK plan for tackling roadside nitrogen dioxide concentrations: Detailed plan [Government report]. https://www.gov.uk/government/publications/air-quality-planfor-nitrogen-dioxide-no2-in-uk-2017 Accessed 10 July 2018.

Department for Transport. (2016, September 8). Public attitudes towards electric vehicles: 2016 (revised) [Statistical release]. https://www.gov.uk/government/uploads/system/uploads/attachment data/file/551446 lelectric-vehicles-survey-2016.pdf Accessed 10 July 2018.

Egbue, O., \& Long, S. (2012). Barriers to widespread adoption of electric vehicles: An analysis of consumer attitudes and perceptions. Energy Policy, 48, 717-729. doi:10.1016/j.enpol.2012.06.009

Foreman, J. (2009, November 29). Copenhagen? Just jump in the private jet, darling. The Sunday Times Magazine, pp. 52-55.

Geek. (n.d.) In Dictionary.com. http://www.dictionary.com/browse/geek Accessed 10 July 2018.

Graham-Rowe, E., Gardner, B., Abraham, C., Skippon, S., Dittmar, H., Hutchins, R., \& Stannard, J. (2012). Mainstream consumers driving plug-in battery-electric and plugin hybrid electric cars: A qualitative analysis of responses and evaluations. Transportation Research Part A, 46, 140-153. doi:10.1016/j.tra.2011.09.008

Grubb, E. L., \& Hupp, G. (1968). Perception of self, generalized stereotypes, and brand selection. Journal of Marketing Research, 5, 58-63. doi:10.2307/3149794 
Heffner, R. R. (2007). Semiotics and advanced vehicles: What hybrid electric vehicles (HEVs) mean and why it matters to consumers (Doctoral thesis, University of California, Davis, US). http://escholarship.org/uc/item/9mw1t4w3 Accessed 10 July 2018.

Heffner, R. R., Kurani, K. S., \& Turrentine, T. (2005). Effects of vehicle image in gasolinehybrid electric vehicles (Institute of Transportation Studies, University of California, Davis research report no. UCD-ITS-RR-05-08). http://www.its.ucdavis.edu/publications/2005/UCD-ITS-RR-05-08.pdf Accessed 10 July 2018.

Hattersley, G. (2009, November 29). The green gloss code. The Sunday Times Magazine, pp. 28-31.

Hutchings, K. (2005). Don't call me a tree hugger! Sticks, stones, and stereotypes in ecocriticism. Interdisciplinary Literary Studies, 7(1), 5-26. http://www.jstor.org/stable/41209926 Accessed 10 July 2018.

Jorgensen, B. (2011, October). Granola-eating, Birkenstock-wearing tree-huggers who want to take your guns: Reframing the rhetoric of sustainable agriculture. Paper presented at the 2011 IEEE International Professional Communication Conference, Cincinnati, Ohio, US. http://ieeexplore.ieee.org/stamp/stamp.jsp?tp=\&arnumber $=6087205$ Accessed 10 July 2018.

Lesko, A. C. \& Corpus, J. H. (2006). Discounting the difficult: How high math-identified women respond to stereotype threat. Sex Roles, 54(1/2), 113-125. doi:10.1007/s11199-005-8873-2 
Laker, L. (2018, May 4). Highly charged: complaints as electric car points block city pavements. https://www.theguardian.com/cities/2018/may/04/charged-complaintselectric-car-points-pavements-pedestrians Accessed 26 September 2018.

Le Vine, S. (2012, June). Car reference 2.0: Car club innovations and why they matter [Report for the RAC Foundation, UK]. http://www.racfoundation.org/assets/rac foundation/content/downloadables/car_renta 1_2.0-le vine jun12.pdf Accessed 10 July 2018.

Maxwell, J. A. (2010). Using numbers in qualitative research. Qualitative Inquiry, 16(6), 475-482. doi:10.1177/1077800410364740

Office for Low Emission Vehicles. (2013). Driving the future today: A strategy for ultra low emission vehicles in the UK [Government report]. https://www.gov.uk/government/publications/driving-the-future-today-a-strategy-forultra-low-emission-vehicles-in-the-uk Accessed 10 July 2018.

Patton, M. Q. (1990). Qualitative evaluation and research methods. Newbury Park, CA: Sage.

Pennington, C. R., Heim, D., Levy, A. R., \& Larkin, D. T. (2016). Twenty years of stereotype threat research: A review of psychological mediators. PLoS ONE, 11(1), 1-25. doi:10.1371/journal.pone.0146487

Pronin, E., Steele, C. M., \& Ross, L. (2004). Identity bifurcation in response to stereotype threat: Women and mathematics. Journal of Experimental Social Psychology, 40(2), 152-168. doi:10.1016/S0022-1031(03)00088-X

Rogers, E. M. (2003). Diffusion of innovations (5th ed.). New York, NY: Free Press. 
887

888

889

890

891

892

893

894

895

896

897

898

899

900

901

902

903

904

905

906

907

Rose, E. (2003). Computer error: Resisting computer culture. Toronto, ON: Between the Lines.

Rauh, N., Franke, T., \& Krems, J. F. (2015). Understanding the impact of electric vehicle driving experience on range anxiety. Human Factors, 57(1), 177-187. doi:10.1177/0018720814546372

Rubin, H. J., \& Rubin, I. S. (2012). Qualitative interviewing: The art of hearing data (3rd ed.). London: Sage.

Schuitema, G., Anable, J., Skippon, S., \& Kinnear, N. (2013). The role of instrumental, hedonic and symbolic attributes in the intention to adopt electric vehicles. Transportation Research Part A, 48, 39-49. doi:10.1016/j.tra.2012.10.004

Sekaquaptewa, D., \& Thompson, M. (2003). Solo status, stereotype threat, and performance expectancies: Their effects on women's performance. Journal of Experimental Social Psychology, 39(1), 68-74. doi:10.1016/S0022-1031(02)00508-5

Shapiro, J. R., \& Neuberg, S. L. (2007). From stereotype threat to stereotype threats: Implications of a multi-threat framework for causes, moderators, mediators, consequences, and interventions. Personality and Social Psychology Review, 11(2), 107-130. doi:10.1177/1088868306294790

Skippon, S. M., Kinnear, N., Lloyd, L., \& Stannard, J. (2016). How experience of use influences mass-market drivers' willingness to consider a battery electric vehicle: A randomised controlled trial. Transportation Research Part A: Policy and Practice, 92, 26-42. doi:10.1016/j.tra.2016.06.034 
908

909

910

911

912

913

914

915

916

917

918

919

920

921

922

923

924

925

926

927

928

929

Smith, J. A., \& Osborn, M. (2008). Interpretative phenomenological analysis. In J. A. Smith (Ed.), Qualitative psychology: A practical guide to research methods (pp. 53-80). London: Sage.

Society of Motor Manufacturers and Traders. (2018, January 5). December - EV registrations [Statistical release]. https://www.smmt.co.uk/2018/01/december-ev-registrations/ Accessed 10 July 2018. (a)

Society of Motor Manufacturers and Traders. (2018, July 5). June - EV registrations [Statistical release]. https://www.smmt.co.uk/2018/07/june-ev-registrations/ Accessed 10 July 2018. (b)

Sowden, L. J. \& Grimmer, M. R. (2009). Symbolic consumption and consumer identity: An application of social identity theory to car purchase behaviour. Paper presented at the 2009 ANZMAC Conference, Melbourne, Australia. https://pdfs.semanticscholar.org/c493/679b922a4201899d33036bf34e4b843a565f.pdf Accessed 10 July 2018.

Spencer, S. J., Steele, C. M., \& Quinn, D. M. (1999). Stereotype threat and women's math performance. Journal of Experimental Social Psychology, 35(1), 4-28. doi:10.1006/jesp.1998.1373

Steele, C. M. (1997). A threat in the air: How stereotypes shape intellectual ability and performance. American Psychologist, 52, 613-629. doi:10.1037/0003-066X.52.6.613

Steele, C. M., Spencer, S. J., \& Aronson, J. (2002). Contending with group image: The psychology of stereotype and social identity threat. Advances in Experimental Social Psychology, 34, 379-440. doi:10.1016/S0065-2601(02)80009-0 
930

931

932

933

934

935

936

937

938

939

940

941

942

943

944

945

946

947

948

949

950

Steg, L. (2005). Car use: Lust and must. Instrumental, symbolic and affective motives for car use. Transportation Research Part A, 39, 147-162. doi:10.1016/j.tra.2004.07.001

Steg, L., Vlek, C., \& Slotegraaf, G. (2001). Instrumental-reasoned and symbolic-affective motives for using a motor car. Transportation Research Part F, 4, 151-169. doi:10.1016/S1369-8478(01)00020-1

Sunday Times Driving. (2013, June 10). Clarkson on: The environment. https://www.driving.co.uk/news/clarkson-on-the-environment/ Accessed 10 July 2018.

Tajfel, H. (1978). Differentiation between social groups. London: Academic Press.

Tajfel, H., \& Turner, J. C. (1979). An integrative theory of intergroup conflict. In W. G. Austin \& S. Worchel (Eds.), The social psychology of intergroup relations (pp. 33-48). Monterey, CA: Brooks/Cole.

Tajfel, H., \& Turner, J. C. (1986). The social identity theory of intergroup behaviour. In S. Worchel \& W. G. Austin (Eds.), Psychology of Intergroup Relations (pp. 7-24). Chicago, IL: Nelson-Hall.

Technophile. (n.d.) In Cambridge Dictionary. https://dictionary.cambridge.org/dictionary/english/technophile\#translations Accessed 10 July 2018.

Thurlow, C., \& Jaworski, A. (2006). The alchemy of the upwardly mobile: Symbolic capital and the stylisation of elites in frequent-flyer programmes. Discourse and Society, 17(1), 99-135. doi:10.1177/0957926506058066 
951 Transport for London. (2016, April). Electric vehicles: Gauging interest among disabled and

952

953

954

955

956

957

958

959

960

961

962

963

964 elderly drivers. http://content.tfl.gov.uk/gauging-interest-for-evs-among-disabled-andelderly-drivers.pdf Accessed 26 September 2018.

White, K., \& Argo, J. J. (2009). Social identity threat and consumer preferences. Journal of Consumer Psychology, 19(3), 313-325. doi:10.1016/j.jcps.2009.03.007

White, K., Argo, J. J., \& Sengupta, J. (2012). Dissociative versus associative responses to social identity threat: The role of consumer self-construal. Journal of Consumer Research, 39(4), 704-719. doi:10.1086/664977

White, K., \& Dahl, D. W. (2007). Are all outgroups created equal? Consumer identity and dissociative influence. Journal of Consumer Research, 34(4), 525-536. doi:10.1086/520077

White, L. V., \& Sintov, N. D. (2017). You are what you drive: Environmentalist and social innovator symbolism drives electric vehicle adoption intentions. Transportation Research Part A: Policy and Practice, 99, 94-113. doi:10.1016/j.tra.2017.03.008 